\title{
Sciendo
}

HOLISTICA Vol 9, Issue 2, 2018, pp. 153-1598

DOI:10. 2478/hjbpa-2018-0018

\section{More challenging and complex responsibilities in current jobs}

\author{
Magdalena VELCIU, \\ National Research Institute for Labour and Social Protection - INCSMPS, Romania
}

\begin{abstract}
In this article, we give some remarks on how the recent evolution of work tasks and job responsibilities come in relation with challenging and high competitive work environment. Analyse is based on self-assessment of how job responsibilities and problem solving is perceived in the opinion of employed persons. Finally, many Romanian employed persons said that their responsibilities are more challenging and complex, especially in last years, demanding their great effort to adapt and fulfil objectives. These conclusions are important because if we have a correct interpretation of work environment challenges, evolutions and responsibilities, we can imagine the best alternatives to cope with the change in the workplace and improve adaptive performance.

Keywords: job responsibilities, work environment, adaptive performance

JEL Classification: 12.
\end{abstract}

\section{The context}

The last evolutions have profoundly changed the society in general and the world of work in particular. The work process is deeply influenced by the transformations generated by dynamic changes in technology, massive infiltration of computerization processes in all fields and development of computer science also the modernization of requirements of a highly active market economy. The most digitally mature organizations are more than four times more likely to be developing needed digital leaders than the least digitally mature ones (Kane G.C., 2018).

Also globalization leads to many changes in the working environment. The full impact of globalization in the workplace has yet to be realized, but as more companies embrace this trend and become more diverse, certain changes are emerging (Mc Farlin K., 2018). While many of these changes are good, others may not be as positive. The challenges could be: increased cultural diversity, increased standards and competition, job losses etc. 
While the imminent change is a great promise, patterns of consumption, production and employment created by it also pose major challenges requiring proactive adaptation by corporations, governments and individuals (World Economic Foorum, 2016).

Overall, they all put some pressure on employee capacity to fulfil their job responsibilities and force the employer's ability to react efficiently with best managerial practices and decisions. For instance, lifelong learning is only a first starting point.

In these challenging environment, the education and vocational have to be a priority to facilitate progress and permit employees to keep up with the changes and give them competences and abilities to meet organizational goals, respectively complex tasks and responsibilities, in a high-performance context and competitiveness.

Adaptive performance (Pulakos and col., 2000) is essential for employees and teams reflecting the capacity to cope with change in the work environment. An employee who is adaptable and achieves professional tasks is able to obtain performance.

Also, managers are looking for well-trained employees with high adaptability, positive attitude to change, and ability to learn. Performance is about making quick decisions when faced with one emergency, dealing with high demand tasks, solve complex problems, approach new methods and technological problems in order to accomplish a work task, good interpersonal relations and intercultural abilities and so on.

\section{The methodology}

The research methodology is based on self-evaluation method that provides a high degree of confidence for the data collected and will facilitate indepth understanding of the information gathered. The questionnaire based survey is addressed to employed persons with higher education level, in a total of 1200 persons. The tool is structured questionnaire with the following structure: individual data, job data, qualifications and skills, job requirements and responsibilities. Data was collected at the end of 2017. I will present the main results and conclusions (Figure no 1 ).

\section{The results: Evolution of job responsibilities and problem solving}

Difficulties like technical change, technological innovation and computer science development, rate of renewal and so on means continue changes and fluctuations in the work environment and increased difficulty and put additional 
pressure on the employee's ability to due their jobs. Directly, the tasks and responsibilities of the employee have become complex. This is perceived by the employees in the Romanian active enterprises.

Training is essential. The need to learn new things comes into our sight; because it connects the work with the latest technologies, IT alternatives, working methods, etc. and facilitate generating innovative ideas, methods, and new products for adding value.

The investigated subjects that the need to learn new things has remained constant (47.1\%) and $46.4 \%$ said that they have to learn continuously over the last three years. A very small part said that need for learning new things has diminished. The results are in relation with other variables such as years of work, field of activity, career, competition etc.

Strategic thinking and need to plan activities are necessary for the employee's capacity to manage a variety of activities and achieve the performance goals of organization.

A percentage of $50.8 \%$ of all respondents said that the need for planning remained constant over the last three years, but $41.6 \%$ of them remarked an intensification of these requirements. This means the "mass spreading” of the strategic thinking that is no longer just the task of the manager, but of each individual, so the vision must be seen as a process integrated into his/her own job.

Responsibility for decision-making is defined by the ability to find answers and make good decisions for the firm, on the basis of the information gathered and carefully analysed. The smart employees analyses all the facts and alternatives before deciding on the most appropriate solution. The decision-making responsibilities seeming increased for $45.8 \%$ of the participants in the last three years.

The complexity of work tasks and responsibilities refers to knowing and analyzing all the consequences of its actions and professional alternatives as well as identifying and concentrating personal efforts on important and urgent matters. The complexity of tasks and responsibilities is perceived as increasing by half of employees, respectively $50.3 \%$ in the last three years. Only $42.7 \%$ of employees perceived that tasks and responsibilities have remained the same.

The variety of work tasks and responsibilities refers to the many different types of tasks the employees have and the pressure to proper fulfil them. A percentage of $49.3 \%$ of all interviewed persons said that the variety of work and responsibilities remained constant over the past three years, but $45.0 \%$ of them perceive an accentuation of these demands.

Diversity and working in diverse teams' means intercultural, multidisciplinary, many fields of activity etc., reflects the need to interact with 
many people and groups to exchange information, to cooperate and support the work objectives. It supports the common aim and shoe professional specialization on specific tasks, but also the need to reintegrate the parties into a unitary whole. It is directly related to economic efficiency.

In our survey, there is an increase in the need for diverse team working that is noted by $37.9 \%$ of the total subjects, just for the last three years. However, in the modern work environment, this ability has grown steadily in relation with complexity of business environments.

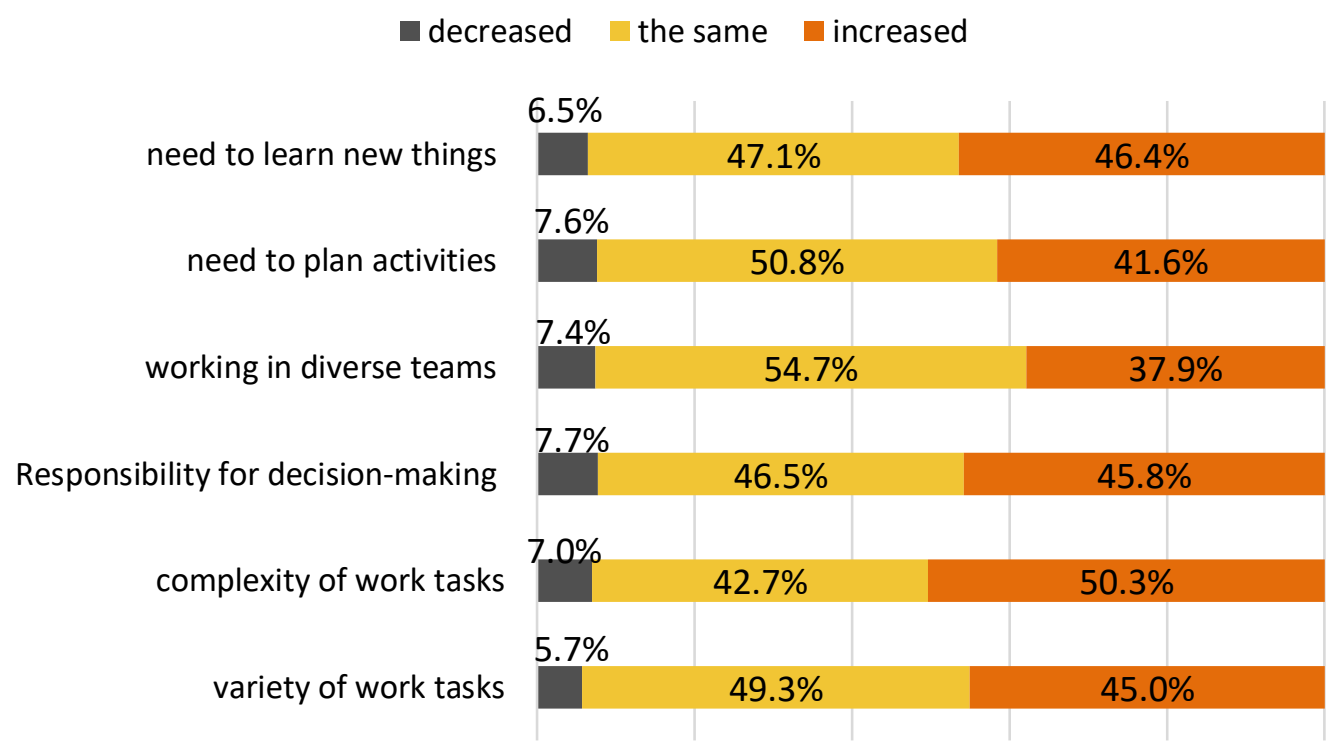

Figure no 1: Evolution of specific issues of work and responsibilities

Solving complex problems along with results-oriented attitude has become essential in today's challenging, competitive environment. Employees need to apply the ability to solve problems to manage the challenges, opportunities and work situations that appear, relying on their own training, trusted on accumulated knowledge and previous experiences, and so on, searching for other alternatives. When a complex problem arises, four successive steps are required in the solving process: defining the problem, generating alternatives, evaluating and selecting best alternative, implementing solutions.

Often, the speed of problem solving is a very important criterion of efficiency.

For example, we ask employed persons how often they are confronted with complex problems at the job and need to quickly find best solutions, let's say in less than $\mathbf{3 0}$ minutes, two out of five employees are faced with the need to 
quickly solve complex problems. Of these, $14.7 \%$ face complex problems every day and solve them, and $24.4 \%$ face at least once a week with the need to quickly solve complex problems (Figure 2). Another part of the employees (26.9\%) face complex problems less than once a week, while others (18.9\%) state that very rarely, less than once a month, they are in a situation of solving problems complex. Only a small percentage, of $15.1 \%$ of the employees, said that they do not have to solve complex problems.

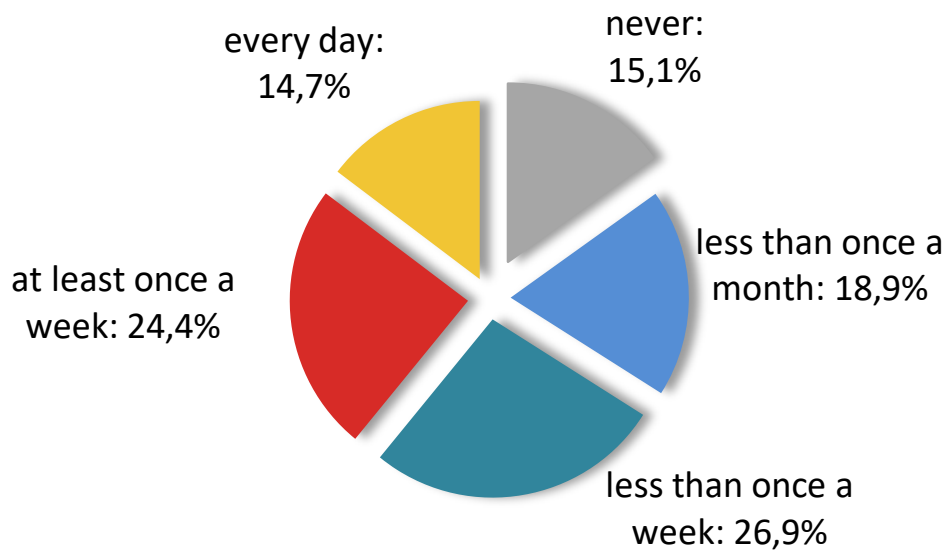

Figure no 2: How often employees are faced with complex problems and have to find solutions quickly in less than 30 minutes?

\section{Final remarks}

The last evolutions of challenging and high competitive work environment put some pressure on employee capacity to fulfil their job responsibilities and organizational objectives. These force the employer's ability to react efficiently with best managerial practices and decisions; also the education and vocational training have to be a priority to facilitate progress and permit employees to keep up with the complexity and give them competences and abilities to meet organizational goals. Finally, the tasks and responsibilities of the employee increased and have become complex.

Challenges and increased job difficulties at workplace claim a need for more education and training. In order to help employees to face the new challenges, managers have to implement policies and offer training and learning through reflection on doing, to make sure everyone can adapt and perform, through the mobilization and efficient use of human resources, in a context of high performance and competitiveness. 


\section{Reference}

[1] Pulakos, E. D., Arad, S., Donovan, M. A., \& Plamondon, K. E. (2000). Adaptability in the workplace: development of a taxonomy of adaptive performance. Journal of Applied Psychology, 85(4), 612-624.

[2] Kane Gerald C., Doug Palmer, Anh Nguyen Phillips, David Kiron, and Natasha Buckley, Coming of Age Digitally, MIT Sloan Management Review, 2018

[3] McFarlin Kate, The Effects of Globalization in the Workplace, Updated June 30, 2018, available at https://smallbusiness.chron.com/effects-globalization-workplace-10738.html

[4] http://reports.weforum.org/future-of-jobs-2016/preface/ 